\title{
BMJ Open Exploring the experiences of people in Ontario, Canada who have trouble affording medicines: a qualitative concept mapping study
}

\author{
Hannah Yaphe, ${ }^{1}$ Itunuoluwa Adekoya, ${ }^{1}$ Liane Steiner, ${ }^{1}$ Darshanand Maraj, ${ }^{1}$ \\ Patricia O'Campo, ${ }^{1,2}$ Nav Persaud (D) ${ }^{1,3,4}$
}

To cite: Yaphe H, Adekoya I, Steiner L, et al. Exploring the experiences of people in Ontario, Canada who have trouble affording medicines: a qualitative concept mapping study. BMJ Open 2019;9:e033933. doi:10.1136/ bmjopen-2019-033933

- Prepublication history for this paper is available online. To view these files, please visit the journal online (http://dx.doi. org/10.1136/bmjopen-2019033933).

HY and IA contributed equally.

HY and IA are joint first authors.

Received 29 August 2019

Revised 28 November 2019

Accepted 03 December 2019

Check for updates

(C) Author(s) (or their employer(s)) 2019. Re-use permitted under CC BY-NC. No commercial re-use. See rights and permissions. Published by BMJ.

${ }^{1}$ MAP Centre for Urban Health Solutions, St. Michael's Hospital, Toronto, Ontario, Canada ${ }^{2}$ Dalla Lana School of Public Health, University of Toronto, Toronto, Ontario, Canada ${ }^{3}$ Department of Family and Community Medicine, University of Toronto, Toronto, Ontario, Canada

${ }^{4}$ Department of Family and Community Medicine, St Michael's Hospital, Toronto, Ontario, Canada

Correspondence to

Dr Nav Persaud;

nav.persaud@utoronto.ca

\section{ABSTRACT}

Objectives The experiences of people who report costrelated medicine non-adherence are not well documented. We aimed to present experiences relating to accessing medicines reported by the participants in a randomised controlled trial of free medicine distribution.

Methods The trial consisted of primary care patients from a large urban family practice and three rural family practices who reported cost-related medicine non-adherence. Participants were randomly allocated to continue their poor access (control) or to receive free and easily accessible medicines (intervention). As part of data collection for the first year of the trial, participants were asked closed and open-ended questions to assess their adherence to medication, health outcomes and their experiences in relation to medicine accessibility. We conducted a qualitative concept mapping study in which we analysed and summarised participants' responses to the open-ended question on a concept map to visually present their experiences relating to accessing medicines. Results Of the 524 trial participants contacted, 198 (38\%) responded to the open-ended question. The concept map contains clusters that represent eight types of experiences of participants related to medicine access including stress, relationship with doctor, health impact, quality of life, sacrificing other essentials, medicines are expensive, financial impact and adherence. These experiences fall under two major themes, experiences relating to personal finances and experiences relating to well-being, which are bridged by a central cluster of adherence.

Conclusions The experiences shared by the participants demonstrate that access to medicines impacts people's finances and well-being as well as their adherence to prescribed medicines. These results indicate that effects on personal finances and general well-being should be measured for interventions and policy changes aimed at improving medicine access.

Trial registration number This article is linked to the Carefully Selected and Easily Accessible at No Charge Medicines (CLEAN Meds) randomised controlled trial (trial registration number: NCT02744963).

\section{INTRODUCTION}

The experiences of people who cannot afford medicines and report cost-related
Strengths and limitations of this study

- This is the first study that explores and presents patient experiences of cost-related medicine nonadherence using a concept map.

- The concept map reflects experiences from a large clinical population with diverse socioeconomic backgrounds, geographical locations and healthcare needs.

- Although the sample size is sufficient for a concept mapping study ( $n=198)$, the response rate to the open-ended question was low (38\%) and responses from people with stronger views (positive or negative) may be over-represented in the concept map.

- Participants receiving free medicine distribution contributed more responses (72\%) than those with the usual access (28\%) so these results mostly reflect the experiences of people who went from having poor medicine access to having better access.

medicine non-adherence are not well characterised in multiple high-profile reports that focus on health and economic effects of medicine access. ${ }^{1-5}$ Few qualitative studies have specifically explored the experiences of people who report cost-related medicine non-adherence. ${ }^{6-9}$ The rates of medicine non-adherence range between $30 \%$ and $40 \%$ for chronic disease treatments in low-, middle- and high-income countries. ${ }^{1}$ Approximately $10 \%$ of Canadians who receive a prescription report cost-related medicine non-adherence. ${ }^{3}$ Canada remains the only developed country with a universal public health insurance system that does not include coverage of prescription medicines, despite multiple governmental and academic reports over the past several decades recommending implementing universal pharmacare. ${ }^{5}$

Sharing people's experiences has played a role in influencing policy changes in the past. In response to a report by the Canadian Standing Senate Committee of Social Affairs 
which supplemented official recommendations with Canadians' stories and experiences relating to mental health, the federal government created the Mental Health Commission of Canada. ${ }^{11}$ Strong community advocacy for supervised injection and overdose prevention sites has led to the establishment and continued operation of these facilities in cities across Canada. ${ }^{12-14}$ Clients of Insite (a supervised injection site in Vancouver) shared their experiences in Canada (Attorney General) v. Portland Hotel Society (PHS) Community Services Society, a Supreme Court challenge resulted in a ruling which allowed Insite to remain open. ${ }^{15} 16$ Exploring and understanding the experiences of people with poor medicine adherence might help promote policy changes that improve health and well-being. Understanding the relationship between the different experiences of people who have trouble affording medicines could also help to direct future research.

The purpose of this qualitative concept mapping study was to describe and represent experiences relating to accessing medicines that were reported by participants during the first year of a randomised controlled trial of free medicine distribution. ${ }^{17}{ }^{18}$ Concept mapping is a participatory methodology used to visually represent the ideas or thoughts of an individual or group and it is suitable for analysing responses to open-ended survey questions. ${ }^{19}$ The trial included people who reported not taking a prescribed medicine for a chronic condition because of the cost and were randomly allocated to either continue their poor access or to have free distribution of essential medicines. ${ }^{17} 18$ Thus, the reported experiences include those of people who have poor medicine access and those who have improved access, similar to what might happen if there was a change in public policy surrounding medicine access.

\section{METHODS}

\section{Data collection}

As part of collecting study outcome data from participants in the CLEAN Meds randomised controlled trial, we phoned participants enrolled in the trial. Recruitment and data collection methods as well as results from the trial are provided elsewhere. ${ }^{18}$ Briefly, patients who had reported cost-related non-adherence were recruited from a large urban family practice and three rural family practices. The results from that trial indicated that the provision of free medicines improved adherence and some surrogate health outcomes. ${ }^{18}$

During the data collection for the main trial, several close-ended questions were asked including questions focusing on the patient-doctor relationship, the medication delivery system, information participants had received about the medications, participants' perceived health and ability to make ends meet. The responses to the closed-ended questions are reported elsewhere. ${ }^{18}$ After these closed-ended questions, participants were given the option of responding to an open-ended question: 'Is there anything else you would like to say?' Responses to this open-ended question are the subject of this study.

All study outcome questions, including the open-ended question, were developed by a community guidance panel (CGP) for the trial ${ }^{20}$ and were pilot tested before being implemented. ${ }^{17}$ The study was approved by the Research Ethics Board of St Michael's Hospital where data collection was conducted from March 2017 to October 2018 by trained research assistants who had previously completed certifications in Canada Good Clinical Practice and Tri-Council Policy Statement 2. Data collection was approximately 10-20 min per participant and responses were entered into Research Electronic Data Capture (REDCap) V.8.5.11, a web-based survey software, as they were provided.

\section{Creating units of analysis}

Similar to the methods described by Jackson and Trochim for the use of concept mapping for survey results, responses to the open-ended question were broken down into shorter sentences or units (statements) containing a single concept or idea. ${ }^{19}$ To ensure the unitisation process was reliable, two researchers (IA, female, research assistant; HY, female, research assistant) agreed on the unitisation criteria, independently made unitising decisions and then made final decisions together on each statement. In cases of disagreement, a tie breaker (DM, male, research assistant) was used to make a final decision.

We (IA and HY) reviewed the complete set of units and removed redundant or duplicative statements. For these cases, we retained a single statement phrase that was representative of the group of similar statements. We further refined the set to include only statements which directly addressed the research question (assessing the experiences of people with respect to medicine accessibility). We removed comments relating to participants': views on how the study was conducted, gratitude for the study (as this was anticipated based on the nature of the study), opinions on the medicine delivery service (this will be addressed in a separate study), views on healthcare and health policy and opinions on the acceptability of the short list of medicines (this was addressed in a separate study). ${ }^{21}$ Each statement in the condensed set was given a unique identifying number and printed on a card.

\section{Sorting}

Due to the nature of the study and the number of participants that provided responses, we had proxy sorters perform the sorting. The use of proxy sorters is accepted in concept mapping for open-ended survey responses. ${ }^{19}$ The proxy sorters included members of the CGP for the trial (four females), ${ }^{20}$ members of the trial research team (IA, HY, DM and LS, female, research assistant, NP, male, principal investigator) and the study pharmacist (male). Since CGP members were involved in the trial design and had direct or indirect experience with barriers to medicine access, we believed that they could appropriately represent the experiences of participants. We also 
thought that research assistants and the study pharmacist would be appropriate sorters due to their extensive experience interacting with trial participants (interactions were only through the trial).

At a single session, sorters received all the cards containing the condensed set of the original statements as described earlier. Each card contained a single statement and sorters were asked to sort them into groups of statements with similar themes as they deem appropriate and label each pile with the topic of the theme. There was no limit to the number of piles the sorters were allowed to create, however, they were not allowed to create a 'miscellaneous' or 'other' piles. We allotted 1 hour for the task and at the end of the exercise, the labelled piles from individual sorters were collected for analysis.

\section{Analysis}

The sorted data were analysed using the R-CMap package for R (V.3.5.3, 3-March-19, 'The Greater Truth'). ${ }^{22}$ R-CMap uses multidimensional scaling to produce a two dimensional point map where each point represents a statement. The distance between two points (but not the absolute location) reflects how frequently the statements were sorted together and shows how related they are. R-CMap also conducts hierarchical cluster analysis using Ward's algorithm, to produce cluster map solutions. Cluster maps define groupings of similar statements on the point map and in this case, would define distinct themes that represent the different types of experiences of people who have trouble affording medicines.

We obtained both a point map and the range of possible cluster map solutions for the sorted data. The final cluster solution was determined by the research group by qualitatively assessing the statements placed in each cluster for each solution as previously described. ${ }^{19}$ Cluster titles were decided by considering the contents of each cluster and the titles given by sorters to similar groupings in the raw sorting data.

\section{Patient and public involvement statement}

Four community members, who were involved in developing the original trial with the research team, were involved in data sorting for this study.

\section{RESULTS}

The characteristics of participants in the trial of free medicines who responded to the open-ended question are shown in table 1. Most were white and about $60 \%$ were women. Participants received income from a variety of sources, the most common being wages and salaries. Approximately half of the participants had household incomes less than $\$$ C30000 per year. The demographics of all the participant in the trial of free medicine distribution are presented in the main trial article. ${ }^{18}$

Of the 786 total participants enrolled in the CLEAN Meds trial, we were able to reach $524(67 \%)$ by phone; the others not reached (262) were due to lost contact,
Table 1 Participant demographics

\begin{tabular}{|c|c|c|}
\hline & $\begin{array}{l}\text { Free distribution } \\
\text { number }(\%) \\
(n=142)\end{array}$ & $\begin{array}{l}\text { Usual access } \\
\text { number }(\%) \\
(n=56)\end{array}$ \\
\hline Women & $81(57.0)$ & $34(60.7)$ \\
\hline Age (mean, SD) & $52.7 \pm 12.3$ & $51.6 \pm 13.0$ \\
\hline \multicolumn{3}{|l|}{ Ethnicity } \\
\hline White & $96(67.6)$ & $39(69.6)$ \\
\hline Black & $15(10.6)$ & $7(12.5)$ \\
\hline $\begin{array}{l}\text { Southeast or East Asian } \\
\text { (including Korean, Japanese, } \\
\text { Filipino, Chinese) }\end{array}$ & $13(9.2)$ & $0(0)$ \\
\hline South Asian & $7(4.9)$ & $\leq 5$ \\
\hline Latin American & $\leq 5$ & $\leq 5$ \\
\hline Indigenous & $\leq 5$ & $\leq 5$ \\
\hline West Asian (including Arab) & $\leq 5$ & $\leq 5$ \\
\hline Mixed or other & $7(4.9)$ & $\leq 5$ \\
\hline Declined to provide & $0(0)$ & $\leq 5$ \\
\hline \multicolumn{3}{|l|}{ Main Income source } \\
\hline $\begin{array}{l}\text { Wages and salaries (including } \\
\text { self-employed) }\end{array}$ & $84(59.2)$ & $26(46.4)$ \\
\hline Pension & $20(14.1)$ & 10 (17.9) \\
\hline $\begin{array}{l}\text { Social support (eg, welfare or } \\
\text { disability) }\end{array}$ & $10(7.0)$ & $11(19.6)$ \\
\hline Unemployment insurance & $6(4.2)$ & $\leq 5$ \\
\hline Other & $20(14.1)$ & $\leq 5$ \\
\hline Declined to provide & $\leq 5$ & $\leq 5$ \\
\hline \multicolumn{3}{|l|}{ Household income } \\
\hline$\$ C 30000$ or less & $76(54.2)$ & $28(48.2)$ \\
\hline$\$ C 30000-\$ C 70000$ & $46(33.1)$ & $19(32.1)$ \\
\hline$\$ C 70000$ or greater & $10(7.0)$ & $6(10.7)$ \\
\hline Urban site & $98(69.0)$ & $44(78.6)$ \\
\hline Rural site & $44(31.0)$ & $12(21.4)$ \\
\hline
\end{tabular}

withdrawal from the study or death. Of the 524 contacted, $198(38 \%)$ trial participants responded to the optional, open-ended question ('Is there anything else you would like to say?'), resulting in 295 distinct statements. Of the 198 participants who responded to the open-ended question, $142(72 \%)$ received the trial intervention and these intervention participants contributed $220(74.6 \%)$ of these distinct statements. The mean number of phrases per person was similar between participants who did and did not receive the trial intervention $(1.5 \pm 0.69$ vs $1.3 \pm 0.64$ ). The final condensed set (after data cleaning) contained 41 unique statements.

Ten individuals (four study CGP members and six members of the research team) participated in the structuring (sorting) activity as proxy sorters. All of the sorters completed the task within the allocated time of 1 hour. For the raw sorted data, the median number of sorted piles was 6.5 (IQR: 4.2-7.8).

The point map generated from the raw, sorted data had a stress value of 0.277 indicating a typical 'goodness 
of fit'. The application of hierarchical cluster analysis produced a series of maps with cluster solutions ranging from 3 to 10. The research group arrived at a final solution of eight clusters based on consideration of individual sorting results and qualitative assessment of the possible cluster solutions. At solutions below seven clusters, unrelated statements were grouped together and there was not sufficient resolution of the distinct themes. For solutions that included more than eight clusters, there was an increase in the number of clusters containing two or fewer statements, and the additional clusters did not introduce distinct concepts. The final eight-cluster solution was selected over the seven-cluster solution due to the group's agreement that specific experiences relating to medicine costs were distinct from experiences relating to trade-offs or sacrifices made to afford medicines.

The final eight-cluster solution concept map is shown in figure 1 along with the cluster titles. The map represents eight types of experiences of participants related to medicine access.

Two overarching themes emerged from the organisation of clusters on the concept map. Clusters on the left side of the map represent experiences related to personal finances while clusters on the right side of the map

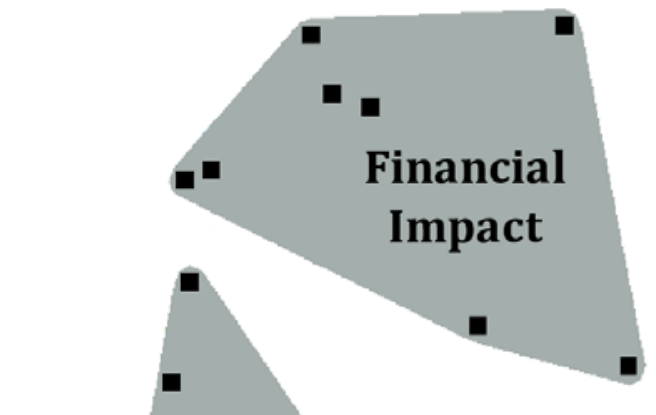

Medicines are

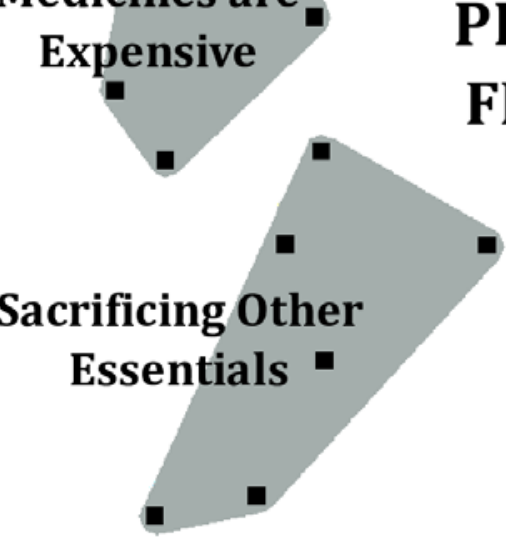

PERSONAL FINANCES

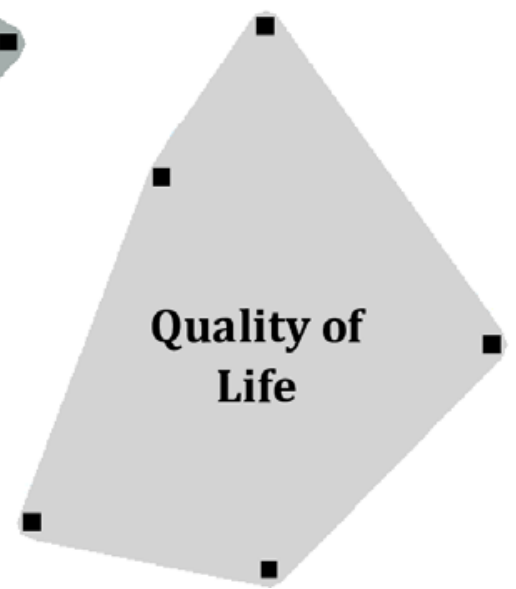

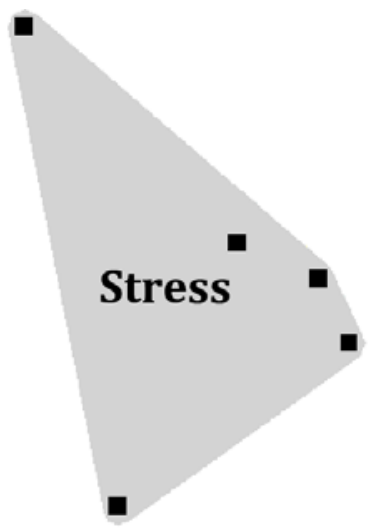

Adherence
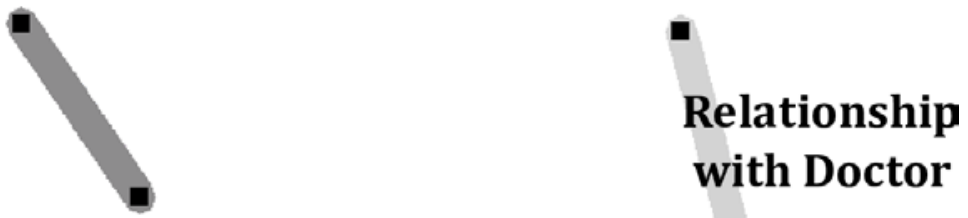

WELLBEING

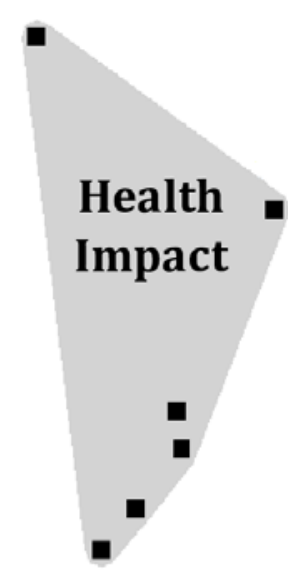

Figure 1 Concept map showing participant experiences relating to medicine access. The map represents eight types of experiences of participants related to medicine access. Two overarching themes emerged from the organisation of clusters on the concept map. Clusters on the left side of the map represent experiences related to personal finances while clusters on the right side of the map represent experiences related to well-being. Statements pertaining to medicine adherence seem to sit between these two groupings, suggesting that sorters regularly connected adherence to other concepts within both affordability and well-being. 
represent experiences related to well-being. Statements pertaining to medicine adherence seem to sit between these two groupings, suggesting that sorters regularly connected adherence to other concepts within both affordability and well-being.

\section{Stress}

This cluster includes several statements which describe feelings of stress with respect to accessing medicines and how improved access to medicines reduced their stress levels.

"The most beneficial part of the study was reduction in stress due to the increased sense of security." - free distribution participant

Others expressed significant stress over the potential loss of medicine coverage after the trial is finished:

"I'm just a little terrified about not having my HIV meds." - free distribution participant

"I am dreading the end of study." - free distribution participant

\section{Relationship with doctor}

Participants felt that access to medicines could promote better communication with physicians.

"[The experience of getting free medicines] helped [me] to be open with [my] doctor." - free distribution participant

"Giving patients access to meds will reduce the number of visits to the doctor for emotional support." - free distribution participant

\section{Health impact}

Some felt that insufficient access to medicines led to negative health consequences.

"I wish I had a medical plan. I have athletes foot and it was a real struggle to get that sorted out." - control participant

In contrast, several participants commented that receiving medicines through the trial intervention led to improvements in their health.

"[The] medicine was very helpful and [my] health is improving." - free distribution participant

Similarly:

"Being a part of this study has helped me to quit smoking and improve my health, I have been smoke free for over a year now..." - free distribution participant

\section{Quality of life}

This cluster describes different broad ways that access to medicines impacted participants' quality of life.

"[It was] frustrating when I could not access free medicine prior to going back to school. Since I went back to school and now have drug coverage, it has improved my quality of life." - control participant
"Where in the past I have had to stretch prescriptions, I haven't had to do that once since being in the study." - free distribution participant

\section{Sacrificing other essentials}

The statements in this cluster highlight the idea that accessing medicines often comes with sacrifices in other areas.

"The sacrifice would have been either poor health due to not being able to fill the prescriptions or filling the prescriptions and having to use the money that I would use for feeding or clothing my children." - free distribution participant

Similarly:

"I have to cut back on food or buy cheap food to be able to afford medications." - control participant

\section{Medicines are expensive}

Medicine prices can be prohibitive for some patients and medicines are generally thought to be very expensive.

“...\$6200 spent on medication and that is a lot of money."

- control participant

"I don't take a medication for my multiple sclerosis because it is \$3000 a month and I can't get funding for it." - control participant

\section{Financial impact}

There seems to be a general connection between medicines and an individual or family's financial situation. Several participants explicitly commented that medicines were not affordable for them (either currently or at some point in the past). Others also noted that buying medicines can have a broader impact on their household or family budget.

"The program has been a life saver to myself and my family in terms of financial means." - free distribution participant

"I was not able to afford my medications." - control participant

\section{Adherence}

Here, participants described how they felt that improved access to medicines changed the way that they took medicines.

"I did not have to miss any to make my medication last longer" - free distribution participant

"I can now take my meds like I am supposed to" - free distribution participant

\section{DISCUSSION}

We identified eight types of experiences that can be organised into two groups-experiences related to personal finances and experiences related to well-beingin addition to a bridging central cluster of adherence. Experiences related to personal finances included the 
ability to afford food and other necessities, and experiences of high medicine costs. Experiences related to wellbeing included stress, the doctor-patientrelationship with doctor and health impact.

The experiences relating to personal finances presented here are consistent with the findings of other studies that have focused on healthcare access, treatment burden or medication adherence. ${ }^{6723-26}$ A previous qualitative study described how the cost of healthcare and particularly the high cost of medicines exacerbated the burden of people with chronic diseases. ${ }^{23}$ Participants in other studies reported making trade-offs for both essential ${ }^{62426} 27$ and non-essential ${ }^{625}$ goods or services to cope with the cost. A typology of cost-related non-adherence suggests that low financial flexibility, a situation where many competing expenses saturate an individual's budget, can lead to cost-related non-adherence regardless of the cost of medicines. ${ }^{692829}$ In our study, participants who received free medicines through the trial intervention frequently described situations of improved financial means or fewer financial compromises. This is also consistent with the main results of our trial which found that those who received medicines were better able to "make ends meet'. ${ }^{18}$ These findings suggest that addressing costrelated non-adherence may have the added effect of alleviating larger financial challenges.

Ourfinding that improved access to medicines enhanced participants' perceptions of their health complements quantitative studies that have found that non-adherence leads to poorer health outcomes. ${ }^{47}$ Conversely, improved adherence or improved access to medicines leads to improved health outcomes. ${ }^{418} 30$ Several participants felt that their health was improving and others reported behaviours such as better communication with a doctor that could potentially lead to better health.

The experiences shared by the participants highlight the harms associated with cost-related non-adherence. Participants spoke about being 'terrified' of losing access to medicines, 'dreading' a lack of medicine coverage after the study, making 'sacrifices' to afford medicines and free medicines being a 'life-saver'. These experiences of harm demonstrate the adverse effects that the current model of prescription drug coverage in Canada has had on disadvantaged Canadians and by extension, the adverse effects that lack of medicine access may have had on disadvantaged people globally. In this sense, experiences of cost-related non-adherence could be understood as experiences of structural violence. Structural violence is caused by injustice and inequity embedded in social institutions ('structure') and causes significant avoidable harm to individuals and communities ('violence') by preventing them from meeting their basic needs (eg, access to the proper standard of healthcare)..$^{31} 32$

\section{Strengths and limitations}

One of the main strengths of this study is that the experiences were collected from a large clinical trial population with a wide range of socioeconomic backgrounds and health needs. This allowed us to capture a large number of diverse responses, which support the generalisability of the experiences shared within the concept map. The sample of individuals who were contacted was large; however, the response rate was only $38 \%$ because commenting was optional; therefore, those who had particularly stronger views (positive or negative) may be over-represented and this should be considered when interpreting the findings and concept map. Furthermore, we did not ask any follow-up questions or further prompting to the original open-ended question, doing so may have improved the response rate and brought out deeper or more insightful comments.

Participants who received the intervention contributed more responses than those in the control group which means that the results mostly reflect the experiences of people who went from having poor medicine access to having better access. Some nuances of the experience of cost-related non-adherence may not have been captured. Although trial participants were told that their responses would not impact their participation in the study, some participants' responses may have been motivated by the hope of maintaining or extending their free access to medicines through the study. While the proxy sorters were carefully selected, they may have overemphasised or de-emphasised statements made by the original respondents; caution should be used when drawing inferences from the concept map. Having participants involved in the sorting process may have added more depth to the categories on the concept map, on the other hand, the proxy sorters may have enhanced the structuring due to their distance from the experiences. ${ }^{19}$

\section{CONCLUSION}

Our findings provide a model for understanding the experiences of those who have trouble affording medicines. Among participants in a trial of free medicine distribution, medicine access was associated with experiences that centred on both personal finances and well-being. These results indicate that future studies of interventions or policies aimed at improving medicine adherence should measure its effects on personal finances (including the ability to buy food and other necessities) and well-being (including perceived health and stress) in addition to measuring adherence. These results also complement the previously demonstrated need for equitable access to medicines by focusing on the experiences of affected people.

Acknowledgements We would like to thank Norman Umali, the CLEAN Meds trial's pharmacist and the four members of the trial's community guidance panel (CGP), Diane Carter, Linda Stella, Sureya Ibrahim and Marleane Davidson who were all proxy sorters for this study.

Contributors HY and IA made substantial contributions to the conception and design of the work, the analysis and interpretation of data for the work and drafted the manuscript; DM and LS made substantial contributions to the acquisition and analysis of data for the work; PO made substantial contributions to the interpretation of data for the work and NP made substantial contributions to the 
conception and design of the work. All authors revised the drafted manuscript critically for important intellectual content, provided final approval of the version to be published and agree to be accountable for all aspects of the work in ensuring that questions related to the accuracy or integrity of any part of the work are appropriately investigated and resolved.

Funding This research received funding from the Canadian Institutes of Health Research (CIHR) and Ontario SPOR (Strategy for Patient-Oriented Research) Support Unit (OSSU) that is jointly funded by the Government of Ontario and the CIHR.

Competing interests None declared.

Patient consent for publication Not required.

Ethics approval Ethics approval for this study was obtained from the St. Michael's Hospital's Research Ethics Board.

Provenance and peer review Not commissioned; externally peer reviewed.

Data availability statement Data are available on reasonable request.

Open access This is an open access article distributed in accordance with the Creative Commons Attribution Non Commercial (CC BY-NC 4.0) license, which permits others to distribute, remix, adapt, build upon this work non-commercially, and license their derivative works on different terms, provided the original work is properly cited, appropriate credit is given, any changes made indicated, and the use is non-commercial. See: http://creativecommons.org/licenses/by-nc/4.0/.

ORCID iD

Nav Persaud http://orcid.org/0000-0003-3327-5580

\section{REFERENCES}

1 Bowry ADK, Shrank WH, Lee JL, et al. A systematic review of adherence to cardiovascular medications in resource-limited settings. J Gen Intern Med 2011;26:1479-91.

2 Lexchin J, Grootendorst P. Effects of prescription drug user fees on drug and health services use and on health status in vulnerable populations: a systematic review of the evidence. Int J Health Serv 2004;34:101-22.

3 Law MR, Cheng L, Dhalla IA, et al. The effect of cost on adherence to prescription medications in Canada. Can Med Assoc $J$ 2012;184:297-302.

4 Osterberg L, Blaschke T. Adherence to medication. N Engl J Med 2005;353:487-97.

5 Morgan SG, Boothe K, eds. Universal prescription drug coverage in Canada: long-promised yet undelivered. Healthcare management forum. Los Angeles, CA: SAGE Publications Sage CA, 2016.

6 Goldsmith LJ, Kolhatkar A, Popowich D, et al. Understanding the patient experience of cost-related non-adherence to prescription medications through typology development and application. Soc Sci Med 2017;194:51-9.

7 Piette JD, Heisler M, Horne R, et al. A conceptually based approach to understanding chronically ill patients' responses to medication cost pressures. Soc Sci Med 2006;62:846-57.

8 Norris P, Tordoff J, Mclntosh B, et al. Impact of prescription charges on people living in poverty: a qualitative study. Research in Social and Administrative Pharmacy 2016;12:893-902.

9 Omojasola A, Gor B, Jones L. Perceptions of generic drug discount programs among low-income women: a qualitative study. Women's Health Issues 2013;23:e55-60.

10 Kirby M. Mental health in Canada: out of the shadows forever. Can Med Assoc J 2008;178:1320-2.

11 Kirby MJ, Keon WJ, Canada. Parliament. Senate, Standing Committee on Social Affairs SaT. Out of the Shadows at Last: Transforming Mental Health, Mental Illness and Addiction Services in
Canada: Final Report of the Standing Senate Committee on Social Affairs, Science and Technology Mental Health, Mental IIIness, and Addiction. LbThe Senate, Ic2006, 2006.

12 Bayoumi AM, Strike CJ. Making the case for supervised injection services. The Lancet 2016;387:1890-1.

13 Shum D. Toronto opens permanent supervised injection site in downtown core, 2017. Available: https://globalnews.ca/news/ 3849927/toronto-permanent-supervised-injection-site/

14 Bruemmer R. Three safe-injection sites Approved for Montreal, 2017. Available: https://montrealgazette.com/news/local-news/three-safeinjection-sites-approved-for-montreal

15 Canada (Attorney General) v. PHS Community Services Society S, 2011SCC 44 (CanLII).

16 Small D. Canada's highest court unchains injection drug users; implications for harm reduction as standard of healthcare. Harm Reduct J 2012;9:34.

17 Persaud N, Lee T, Ahmad H, et al. Protocol for a randomised controlled trial evaluating the effects of providing essential medicines at no charge: the carefully selected and easily accessible at no charge medicines (clean Meds) trial. BMJ Open 2017;7:e015686.

18 Persaud N, Bedard M, Boozary A, et al. Effect of distributing essential medicines at no charge on adherence: the CLEAN Meds randomized clinical trial. JAMA Intern Med 2019. doi:10.1001/ jamainternmed.2019.4472. [Epub ahead of print: 7 Oct 2019].

19 Jackson KM, Trochim WMK. Concept mapping as an alternative approach for the analysis of open-ended survey responses. Organizational Research Methods 2002;5:307-36.

20 Persaud N, Davidson M, Charter D. Community members co-designing a trial of medication access. Can Med Assoc J 2018;190:S44-5.

21 Ally M, Woods $\mathrm{H}$, Adekoya I, et al. What is the acceptability of free access to a short list of essential medicines to patients and their prescribers? a mixed methods study of trial participants. In Press 2019.

22 Bar H, Mentch L, R-Cmap ML. R-CMap-An open-source software for concept mapping. Eval Program Plann 2017;60:284-92.

23 Eton D, Ramalho de Oliveira D, Egginton J, et al. Building a measurement framework of burden of treatment in complex patients with chronic conditions: a qualitative study. Patient Relat Outcome Meas 2012:3:39-49.

24 Goins RT, Williams KA, Carter MW, et al. Perceived barriers to health care access among rural older adults: a qualitative study. The Journal of Rural Health 2005;21:206-13.

25 Sav A, Kendall E, McMillan SS, et al. 'You say treatment, I say hard work': treatment burden among people with chronic illness and their carers in Australia. Health Soc Care Community 2013;35.

26 Heisler M, Wagner TH, Piette JD. Patient strategies to cope with high prescription medication costs: who is cutting back on necessities, increasing debt, or underusing medications? J Behav Med 2005;28:43-51.

27 Bengle R, Sinnett S, Johnson T, et al. Food insecurity is associated with cost-related medication non-adherence in community-dwelling, low-income older adults in Georgia. J Nutr Elder 2010;29:170-91.

28 Walkom EJ, Loxton D, Robertson J. Costs of medicines and health care: a concern for Australian women across the ages. BMC Health Serv Res 2013;13:484.

29 Kovacs PJ, Perkins N, Nuschke E, et al. How end-stage renal disease patients manage the Medicare Part D coverage gap. Health Soc Work 2012;37:225-33.

30 Sommers BD, Blendon RJ, Orav EJ, et al. Changes in utilization and health among low-income adults after Medicaid expansion or expanded private insurance. JAMA Intern Med 2016;176:1501-9.

31 Rylko-Bauer B, Farmer P. Structural violence, poverty, and social suffering. The Oxford Handbook of the social science of poverty 2016:47-75.

32 Farmer PE, Nizeye B, Stulac S, et al. Structural violence and clinical medicine. PLoS Med 2006;3:e449. 